\title{
Cibergêneros nos webjornais brasileiros: um estudo dos dez principais veículos
}

\author{
Clarissa Josgrilberg Pereira \\ Universidade Regional de Blumenau, Blumenau, SC, Brasil \\ ORCID: https://orcid.org/0000-0002-3119-2020
}

\begin{abstract}
Resumo
O fazer jornalístico está em constante alteração e suas transformações são otimizadas pelas tecnologias da informação e da comunicação. Dessa forma, a atual sociedade em rede que vive a convergência da cultura modifica seus hábitos de consumo e de produção de conteúdo. Este cenário atuou como ponto de partida desta pesquisa, gerando-nos a inquietude de compreender qual a relação que os produtos webjornalísticos possuem com as atuais classificações de gêneros e formatos. Para isso, utilizamos uma ficha de análise criada com base em Palacios e Canavilhas e nas classificações de gêneros jornalísticos, que permitiu liberdade e direcionamento para a compreensão da prática jornalística desenvolvida nos dez principais webjornais do país: Folha de S.Paulo, Estado de S. Paulo, Gazeta do Povo, Zero Hora, O Globo, BuzzFeed, Vice, HuffPost Brasil, Nexo e Agência Pública. Foram analisadas 232 unidades, o que nos gerou um banco de dados com mais de oito mil unidades de informação. Este processo constituiu uma macroanálise. A partir dos procedimentos acima expostos, identificamos que na produção do hard news no webjornalismo brasileiro há predominância dos formatos e gêneros hegemônicos. Contudo, identificamos, ainda, que os formatos no webjornalismo atuam com fluidez entre os gêneros jornalísticos, ora servindo de complemento, ora sendo os condutores absolutos dos gêneros.
\end{abstract}

\section{Palavras-chave}

Webjornalismo. Gêneros jornalísticos. Formatos jornalísticos.

\section{Introdução}

A presente pesquisa buscou avançar na compreensão sobre qual a relação que os produtos webjornalísticos possuem com as atuais classificações de gêneros e formatos jornalísticos. Para isso, estudaram-se os principais webjornais do país, dividindo-se a 
amostra em cinco veículos cuja origem fosse do impresso - Folha de S.Paulo, Estado de S. Paulo, Gazeta do Povo, Zero Hora, 0 Globo - e cinco originados na própria Web - BuzzFeed, Vice, HuffPost Brasil, Nexo e Agência Pública. A cada dia do mês de novembro de 2018 foi feita a coleta de dados em um dos veículos da amostra; assim como são dez veículos aqui estudados, cada um foi analisado três vezes, conforme representado no quadro a seguir.

Quadro 1 - Sites analisados por dia

\section{NOVEMBRO}

\begin{tabular}{|c|c|c|c|c|c|c|}
\hline 01 & 02 & 03 & 04 & 05 & 06 & 07 \\
\hline Folha de SP & Estadão & 0 Globo & Zero Hora & Gazeta do Povo & HuffPostBrasil & Vice \\
\hline 08 & 09 & 10 & 11 & 12 & 13 & 14 \\
\hline Buzzfeed & Nexo & Agência Pública & Folha de SP & Estadāo & O Globo & Zero Hora \\
\hline 15 & 16 & 17 & 18 & 19 & 20 & 21 \\
\hline Gazeta do Povo & HuffPostBrasil & Vice & Buzzfeed & Nexo & Agència Pública & Folha de SP \\
\hline 22 & 23 & 24 & 25 & 26 & 27 & 28 \\
\hline Estadão & O Globo & Zero Hora & Gazeta do Povo & HuffPostBrasil & Vice & Buzzfeed \\
\hline 29 & 30 & & & & & \\
\hline Nexo & Agència Püblica & & & & & \\
\hline
\end{tabular}

Fonte: Elaborado pela autora.

Os conteúdos coletados foram analisados por meio de uma ficha de análise, criada com base em Palacios (2011), Canavilhas (2010) e nas discussões de gêneros jornalísticos, cuja codificação dos dados contempla gêneros e formatos jornalísticos e as sete características do webjornalismo.

Ao todo, 232 unidades de análise compõem a nossa amostra. Além desses, indiretamente, foram consultados mais 333 materiais, que foram acessados por meios dos links disponibilizados nos textos de nossa amostra e que foram levados em consideração para a definição do universo. Assim sendo, foram 565 textos consultados e uma amostra de 232 unidades de análise que foram inteiramente consideradas e avaliadas com base em categorias criadas na ficha de análise, a qual foi constituída de nove seções e 38 questões. Com isso, construímos um banco com mais de 8.816 dados, que foram tratados em planilhas criadas em editor de gráficos e planilhas. 
Contudo, para este estudo, nos prenderemos às questões que se centram nos gêneros e formatos jornalísticos e levam em consideração a seção de identificação do conteúdo que nos possibilitasse organizar a amostra (link, título, editoria, veículo) e a segunda seção de identificação dos materiais de análise, que considerou: se a publicação era originária de outra mídia, a temática do conteúdo, a quantidade de fontes utilizadas, o gênero e o formato do conteúdo.

A coleta de dados desta pesquisa levou em consideração todos os conteúdos presentes na primeira e na segunda tela dos webjornais selecionados para a nossa amostra durante o período de 30 dias corridos. Por isso, nem todos os jornais possuem a mesma quantidade de texto analisada. 0 quadro a seguir mostra quantos textos de cada veículo compuseram a amostra.

Quadro 2 - Composição da amostra

\begin{tabular}{|l|c|}
\hline \multicolumn{1}{|c|}{ Veículo } & Quantidade de textos \\
\hline Folha de S.Paulo & 23 \\
\hline Estadão & 26 \\
\hline O Globo & 31 \\
\hline Zero hora & 22 \\
\hline Gazeta & 15 \\
\hline HuffPost Brasil & 28 \\
\hline Vice & 15 \\
\hline BuzzFeed & 29 \\
\hline Nexo & 30 \\
\hline Agência Pública & 13 \\
\hline Total da amostra & $\mathbf{2 3 2}$ \\
\hline
\end{tabular}

Fonte: Elaborado pela autora.

Ressalta-se que o objetivo central da pesquisa não é comparar um veículo com outro, e sim descobrir como se dá a produção jornalística na Web e qual a relação que os produtos jornalísticos possuem com as atuais classificações de gêneros e formatos jornalísticos. Assim sendo, a comparação só será feita quando dela resultar um dado significativo para o alcance do objetivo da pesquisa. 


\section{Os gêneros jornalísticos}

No Brasil, o pioneirismo da discussão de gêneros jornalísticos é atribuído a Luiz Beltrão, primeiro doutor em comunicação do Brasil. O pesquisador defendia a classificação dos gêneros jornalísticos em opinativo, informativo e interpretativo, o que foi publicado por meio das obras Jornalismo opinativo (BELTRÃO, 1980), Jornalismo interpretativo: ideologia e técnica (BELTRÃO, 1976) e Iniciação à filosofia do jornalismo (BELTRÃO, 1960).

Buscando atualizar os estudos de Beltrão (1980; 1976; 1960 ) e tendo como principal critério de seleção a identificação da intencionalidade das mensagens encontradas em pesquisas empíricas, Melo encontrou cinco gêneros: opinativo, informativo, utilitário, interpretativo e diversional; tal resultado foi sistematizado na obra Gêneros Jornalísticos do Brasil (MELO, ASSIS, 2010). Para ele, o informativo “[...] é a articulação que existe, do ponto de vista processual, entre os acontecimentos reais que eclodem na realidade e sua expressão jornalística por meio do relato que visa a informar o receptor do 'que se passa' nessa realidade" (MELO apud COSTA, 2010, p. 50). Esse gênero se subdivide nos seguintes formatos: nota, notícia, reportagem e entrevista.

É pela progressão dos fatos que nota, notícia e reportagem se diferenciariam. A nota seria um relato curto de um fato jornalístico, a notícia, um relato integral e a reportagem, um relato ampliado de um fato (MELO, 2003). Já a entrevista se diferencia por colocar em destaque um protagonista.

O gênero opinativo é o responsável por colocar em destaque a opinião de uma pessoa e/ou do veículo de comunicação. "No caso dos gêneros que se agrupam na área da opinião, a estrutura da mensagem é codeterminada por variáveis controladas pela instituição jornalística." (MELO, 2003, p. 64). Segundo o autor, a mensagem assume duas feições: “[...] a autoria (quem emite a opinião) e a angulagem (perspectiva temporal ou espacial que dá sentido à opinião)" (MELO, 2003, p. 64).

Na classificação de Melo $(2003,2010)$, são nove os formatos que constituem o gênero opinativo. 0 editorial, que é voz do veículo e o local por meio do qual ele se posiciona diante à sociedade; o comentário, o qual consiste num conteúdo analítico realizado por um jornalista; o artigo, que é produzido por um jornalista ou um especializado em determinado assunto ou área do conhecimento e que exprime argumentos e opiniões acerca do tema. 
Há, ainda, a resenha, também conhecida por crítica, que é uma análise de produtos culturais, como livros e filmes; a carta, que é o espaço destinado aos leitores, para que eles exponham suas opiniões; a coluna, que ocupa um espaço fixo e é composta por pequenas notas ácidas e 'furos' de fatos, especialmente da área política e social; e a crônica, que se utiliza de recursos literários para expor uma opinião sobre a realidade (MELO, 2003; MELO, ASSIS, 2010).

0 gênero opinativo possui ainda dois formatos imagéticos: a charge e a caricatura. O primeiro utiliza imagens satíricas acompanhadas de falas irônicas que, juntas, fazem crítica à política e/ou à sociedade. Já o segundo consiste na realização de retratos com características exageradas.

Outro gênero categorizado por Melo e Assis (2010) é o diversional, o qual, “ [...] sem se afastar da trilha da informação, busca torná-la também saborosa, enriquecendo-a com recursos da narrativa da ficção." (WERNECK, 2004, p. 72). Este gênero é composto por dois formatos: a história de interesse humano e a história colorida. Ambas utilizam recursos literários para contar o fato jornalístico, contudo, a primeira explora elementos da vida do personagem, enquanto a segunda explora detalhes e cenários que envolvem o fato (COSTA, 2010).

O gênero interpretativo já havia sido categorizado por Beltrão (1976). Para ele, “0 jornalismo interpretativo é o objetivismo multiangular da atualidade apresentado pelos agentes da informação pública para que nós próprios, os receptores, o analisemos, julguemos e possamos agir com acerto." (BELTRÃO, 1980, p. 45). Assim sendo, ao contrário do que muitos acreditam, o interpretativo não está relacionado à capacidade interpretativa do jornalista, mas sim a de proporcionar elementos para que o leitor interprete.

São quatro os formatos que constituem o gênero interpretativo: dossiê, perfil, enquete e cronologia. 0 dossiê “[...]se apresenta como um 'mosaico' de informações, muitas vezes está relacionado a temas policiais e tem como objetivo complementar os principais textos noticiosos e levar o leitor à própria compreensão do fato noticioso." (PEREIRA, 2013, p. 37). Já o perfil é a narração feita, por vezes em linguagem mais poética, sobre um personagem. A enquete consiste na opinião de pessoas sobre determinado assunto - na televisão ela é conhecida como o 'fala povo'. Por fim, a cronologia é o relato de um fato contado conforme a ordem em que aconteceu.

0 gênero utilitário 
[...] ocupa-se em proporcionar uma variedade de ferramentas necessárias para as atividades práticas da vida diária do cidadão, isso acontece de diversas formas, entre elas, guias, listas, conselhos, mapas e ainda como complementos de matérias informativas. (VAZ, 2013, p. 102).

São seis os formatos que constituem esse gênero. 0 indicador é aquele que interfere diretamente na vida do leitor, passando informações sobre clima, nível do rio etc. A cotação consiste nas variações do mercado, como o valor do dólar e o preço da arroba do boi. Já o serviço indica informações funcionais e de utilidade, como o horário e local de atendimento, documentações necessárias etc., enquanto o roteiro indica produtos culturais (VAZ, 2013).

Ao pesquisar o gênero utilitário, Tyciane Vaz (2010) incluiu outros dois formatos: dica, que são "[...] informações que unem o formato reportagem (relato estendido sobre algum acontecimento) com o formato roteiro (relato resumido sobre as opções de consumo de bens simbólicos) [...]"(VAZ, 2010, p. 128-129), e olho, que são “[...] vestígios de informações utilitárias, muitas vezes em olho ou boxes, complementando o material informativo e instigando o leitor a possibilidade de ação e reação." (VAZ, 2010, p. 128-129),

Em sua tese de doutorado, Vaz (2013) ainda esclarece que o gênero pode apropriarse de formas conhecidas em outros gêneros, e que a intencionalidade na mensagem irá definir a qual gênero o conteúdo pertence. Vaz (2013) autora diz que é como o gênero utilitário se vestir, por exemplo, das formas do informativo.

Não raro, o gênero utilitário se manifesta em forma de nota, notícia, reportagem, e até mesmo em entrevista para expressar um conteúdo que vai além do informe, exerce função de orientar, aconselhar e prestar informação útil. (VAZ, 2013, p. 109-110).

Para ficar mais claro, esquematizamos os gêneros e formatos explicados anteriormente no quadro que segue.

Quadro 3 - Classificação de Melo

\begin{tabular}{|c|c|}
\hline Gêneros de jornalismo & Gêneros do jornalismo/Formato \\
\hline Informativo & Nota, notícia, reportagem e entrevista. \\
\hline Opinativo & $\begin{array}{r}\text { Editorial, comentário, artigo, resenha (crítica), } \\
\text { coluna, crônica, caricatura, charge e carta. }\end{array}$ \\
\hline
\end{tabular}




\begin{tabular}{|c|}
\hline Interpretativo \\
\hline Diversional \\
\hline Utilitário
\end{tabular}

Fonte: Adaptado de Melo (2003) e Melo e Assis (2010).

Partindo de outra perspectiva para classificar os gêneros jornalísticos, Chaparro (2000) discorda da divisão clássica entre informação e opinião que existe no jornalismo. Para o autor, a divisão do jornalismo em informativo e opinativo não se justifica e, ainda, "a conservação desta matriz reguladora esparrama efeitos que superficializam o ensino e a discussão do jornalismo e tornam cínica sua prática profissional.” (CHAPARRO, 2000, p. 100).

Há outros autores que também criticam a divisão entre opinião e informação, como Noci (2004), para quem “[...] a separação entre informação e opinião é equívoca, instável, permeável e, sobretudo, altamente enganosa." (NOCI, 2004, p. 3). Para o autor, quando se passa a abordar a mídia digital, torna-se menos aceitável ainda a divisão entre opinião e informação (NOCI, 2004). Para ele, “[...] não convém, acreditamos, manter a insistência dessa divisão, menos ainda quando se trata de produtos informativos em rede." (NOCI, 2004, p. 4).

Em sua pesquisa, Chaparro (2000) chegou à conclusão de que é essencial à atividade jornalística narrar e argumentar, e nessa atividade informação e opinião se imbricam mutuamente. Com isso, classificou os gêneros em comentário e relato. Melo e Assis (2010, p. 27) acreditam que a contribuição dada por Chaparro (2000) está, principalmente, na definição dada aos gêneros, pois

[...] se não altera substancialmente a compreensão dos gêneros jornalísticos, sua contribuição adquiriu relevância pela precisão que atribuiu ao conceito de gênero, entendido como categoria abrangente, ou classe, agrupando suas variantes em espécies, o que ajudou a ordenar o universo textual, neutralizando a tendência à fragmentação a que minha geração foi induzida pelos pioneiros no estudo dos gêneros jornalísticos. (MELO, ASSIS, 2010, p. 27). 
Chaparro (2000) parte da concepção de que opinião e informação estão sempre presentes na prática jornalística, e a partir de análises empíricas testou a classificação de Marques de Melo e construiu a sua própria. Na compreensão do autor, "As ações jornalísticas são duas: relatar a atualidade; comentar a atualidade." (CHAPARRO, 2008, p. 177). Essas duas ações seriam, para ele, os gêneros jornalísticos, os quais se dividem em 16 espécies (CHAPARRO, 2008). Além disso, “[...] cada um deles se organiza em dois agrupamentos de espécies: as Espécies Argumentativas e as Espécies Gráfico-artísticas, formas de Comentário; e as Espécies Narrativas e as Espécies Práticas, formas de relato." (CHAPARRO, 2008, p. 178).

\section{Os cibergêneros}

No Brasil, Daniela Bertocchi $(2005,2006,2013)$ e Lia Seixas (2009a, 2009b, 2013) foram as que mais se dedicaram ao estudo dos gêneros jornalísticos na Web, embora haja também contribuições de outros importantes pesquisadores, como Longhi (2010, 2011, 2012). Na América Latina, Salaverría (2005, 2014), Noci (2004) e Ureta (2010) são outros importantes nomes dos que também realizaram estudos sobre gêneros ciberjornalísticos.

Ao discutir gêneros jornalísticos, Ureta (2010) aponta que há quatro níveis de gêneros que coexistem na atualidade: repetição (repete gêneros e formatos das outras mídias, tradicionalmente do impresso), enriquecimento (respeita as características do gênero a qual corresponde, mas incorpora características de interatividade, multimídia e hipertexto), renovação (gêneros que são recriados graças às características do ciberespaço, como a infografia) e inovação (criação de gênero específico para o ciberespaço, sem partir de referências anteriores). Após descrever os níveis dos gêneros jornalísticos na internet, a autora sistematiza a classificação, designando uma nova categoria de gêneros: a dos dialógicos. 0 quadro a seguir demonstra a organização feita por Ureta (2010).

Quadro 4 - Classificação de Ureta

\begin{tabular}{|l|l|}
\hline Gêneros informativos & \multicolumn{2}{|c|}{ Notícia } \\
\hline Gêneros interpretativos & Reportagem $\left\{\begin{array}{l}\text { Reportagem de atualidade } \\
\text { Especial temático } \\
\text { Dossiê documental }\end{array}\right.$ \\
\cline { 2 - 2 } & \multicolumn{2}{|c|}{ Crônica } \\
\hline
\end{tabular}




\begin{tabular}{|l|c|}
\hline Gêneros dialógicos & $\begin{array}{c}\text { Entrevista } \\
\text { Fórum ou debate }\end{array}$ \\
& Chat $\left\{\begin{array}{l}\text { Entrevista em linha } \\
\text { Interação com personalidades } \\
\text { Interação entre usuários }\end{array}\right.$ \\
& $\begin{array}{l}\text { Enquete } \\
\text { Gradicionais: editorial, comentário, crítica, carta a diretor, artigo, } \\
\text { coluna, vinheta etc. } \\
\text { Debates em rede: fórum, chat. }\end{array}$ \\
\hline Infografia digital & Infografia individual e coletivas \\
\hline
\end{tabular}

Ao buscarmos a literatura produzida por Raquel Longhi (2010a, 2010b), encontramos o especial multimídia, o qual, para ela, "[...] tem sido usado para definir a webreportagem que se utiliza de elementos multimidiáticos integrados (imagens, sons e texto verbal), sendo também chamado de reportagem multimídia." (LONGHI, 2010b, p. 150). E a autora continua:

[...] ainda que apareça denominado com vários nomes, o formato que entendemos como 'especial multimídia' poderia ser definido levando-se em conta dois aspectos principais: as características de sua linguagem e as características ligadas ao gênero de formato informativo. (LONGHI, 2010b, p. 152).

Longhi (2010b) ainda considera que esse gênero, para se constituir, se utiliza de diversos outros já consolidados, como a entrevista e o documentário. Outro formato identificado por Longhi (2010b) como sendo próprio da Web é o slideshow. A autora trabalha o slideshow como um formato noticioso, por isso o consideramos parte do gênero informativo.

Embora alguns autores identifiquem novos formatos como os citados anteriormente, é fato que vários autores têm como consenso que a notícia é o formato estratégico do meio digital. Raquel Longhi (2010a, 2010b),“O texto jornalístico digital, como gênero específico dos cibermeios, continua a ter a notícia como pilar importante." (NOCI, 2004, p. 160). Notase que, ao mesmo tempo que o suporte oferta a capacidade de aprofundamento e de memória ilimitada, são os textos curtos e imediatos que garantem destaque.

Justamente por notar o papel da notícia no jornalismo digital, Thaís Jorge (2013) se dedicou, exclusivamente, a compreender, em sua tese de doutorado, esse formato. Para ela, “[...] a notícia pode ser continuada ou em série e essas constituem maneiras de apresentação. 
Uma composição em camadas é passível de absorver simultaneamente informações, análises, gráficos e espaço para comentários dos leitores." (JORGE, 2013, p. 230). Jorge (2013) considera o espaço de comentários da notícia, pois acredita que em conjunto com as outras etapas forma o que ela denomina hipernotícia, e também afirma que a notícia está em processo de mutação e ainda não possui uma forma perfeita para o webjornalismo.

Assim como Herrera (2005), a classificação criada por Jorge não identifica novos formatos jornalísticos, e sim os atualiza como novas possibilidades tecnológicas. A ciberentrevista, por exemplo, mantém as características da entrevista, formato tradicional do jornalismo, mas agora ganha a possibilidade de ser feita virtualmente. A chamada, o título-enlace e a matéria em camadas consistem em práticas jornalísticas já existentes, mas agora otimizadas pela capacidade hipertextual da rede. Já o flash, texto curto que fornece alguns elementos de um episódio a ser desdobrado, parece-nos a atualização da nota, se retomarmos Melo (2003), que afirma se tratar de relato curto de um fato jornalístico.

Assim sendo, consideramos que Herrera (2005) contribui ao mostrar a interferência da tecnologia nos formatos já identificados na literatura e ao deixar claro que não está em busca de uma classificação, uma vez que esta é redutora.

\section{As características do webjornalismo}

Para que um conteúdo jornalístico seja considerado adequado ao webjornalismo, ele deve apresentar as seguintes características: hipertextualidade, personalização, convergência, interatividade, memória, ubiquidade e instantaneidade. A princípio, todos poderiam produzir jornalismo com essas características, contudo, a oferta de conteúdo simples, em sua maioria texto e fotos, ainda prevalece na internet. Canavilhas (2014) contextualiza:

Deve ainda salientar-se que a opção pela oferta de conteúdos mais simples está muitas vezes relacionada com a falta de recursos humanos e de equipamentos nos meios de comunicação. A dificuldade na identificação de modelos de negócio próprios para o sector da informação online impossibilita as empresas de investirem nos recursos necessários que permitiriam dar o salto para um novo patamar, nomeadamente na contratação de jornalistas multimédia, designers e programadores. (CANAVILHAS, 2014, p. 4), 
De qualquer forma, as características levantadas pelo autor são essenciais, pois são as responsáveis por diferenciar as produções jornalísticas que são próprias para a internet. Algumas das características não são exclusivas da internet, e sim potencializadas por ela. Podemos exemplificar isso a partir da interatividade, como afirma Rost (2014):

[...] assim como a internet transcende o jornalismo, que tem como forma de expressão a Web, a interatividade também vai além do jornalismo digital, e cola-se nas rotinas de trabalho de todos os jornalistas, independentemente do meio em que trabalhem. (ROST, 2014, p. 53).

Embora explicaremos as características individualmente, é preciso ter ciência de que elas não são autônomas, mas sim correlacionadas. 0 acesso à memória, por exemplo, pode se dar pelo hiperlink presente no hipertexto. Ao se personalizar um conteúdo, também há uma interação, ou seja, várias características só podem se fazer presentes de forma satisfatória se coexistirem com as outras.

A hipertextualidade é a característica que possibilita o surgimento do hipertexto, ou seja, é a "[...] capacidade de ligar textos digitais entre si." (SALAVERRÍA, 2005, p. 30). Portanto, a hipertextualidade garante uma construção textual diferenciada, descentralizada e que possibilita ao leitor certa autonomia para construir seu próprio caminho de leitura. Assim, essa característica é essencial na discussão de gêneros e formatos, pois ela não só conecta textos de distintas esferas comunicativas, como provoca metamorfoses na pirâmide invertida (MIELNICZUK, 2003) e relaciona em um único texto distintas formas de se apresentar o conteúdo, da imagem interativa ao vídeo. Trabalhar com hipertexto é linkar conteúdos, e a hiperligação é uma das características que mais interferem na estética e na estrutura textual.

A customização, a busca por exclusividades e por versões únicas acompanham o mercado com cada vez mais proximidade. Na comunicação, essa tendência pode ser notada pela especialização e pela segmentação do mercado editorial. E é nesse caminho, de o mercado tentar atender cada vez mais às necessidades individuais de seus sujeitos, que a característica personalização se faz presente. Porém, ainda é pouco explorada. A maior parte das publicações feitas na internet ainda segue o formato e a lógica de produção dos outros jornais e as atualizações são feitas sem uma lógica específica e sem conhecimento da rotina de seus usuários. Essas características vão na contramão do que a personalização propõe, como afirma Lorenz (2014): 
Em suma, quando trabalhamos neste espaço, o nosso objetivo fundamental não é criar um produto ou serviço uniforme. Em vez disso, estamos a entrar no negócio de catering para as mais diferentes necessidades dos utilizadores, com várias opções de uso da oferta baseado nas preferências e necessidades. (LORENZ, 2014, p. 139).

A multimidialidade significa muito mais do que o uso de vários meios ou a convergência de várias linguagens. De modo geral, essa característica pode se manifestar em múltiplas esferas: na linguagem, por conciliar diferentes formas de produzir variados textos; na prática jornalística, por exigir que o profissional trabalhe com vários meios, ferramentas, linguagens e temáticas; e, na esfera tecnológica, por reunir diversas plataformas. Assim sendo, Salaverría (2014) considera "[...] como principais para o conceito de multimédia: 1) como multiplataforma, 2) como polivalência e 3) como combinação de linguagens." (SALAVERRÍA, 2014, p. 26). Já Jenkins (2008) aponta para a convergência de conteúdo, de dispositivos terminais e de sistemas de rede.

A interatividade tem interferência direta no modo como os conteúdos jornalísticos são consumidos e produzidos e é uma característica essencial, pois cada vez mais o público tem necessidade de participar e se sentir parte do processo. Segundo Rost (2014),

A interatividade é um conceito ponte entre o meio e os leitores/utilizadores, porque permite abordar esse espaço de relação entre ambas as partes e analisa as diferentes instâncias de seleção, intervenção e participação nos conteúdos do meio. (ROST, 2014, p. 53).

A memória também é uma característica que na internet passa a ser diferenciada das outras mídias, pois neste espaço se torna infinita. Além disso, na internet, o acesso e a busca por recuperação de informações antigas se torna mais viável e rápida. Todavia, é preciso ter clara a noção de que a memória no jornalismo não surge com a internet, apenas é otimizada com ela.

Para Marcos Palacios (2014), a memória é inata ao jornalismo, pois

O jornalismo é memória em ato, memória enraizada no concreto, no espaço, na imagem, no objeto, atualidade singularizada, presente vivido e transformado em notícia que amanhã será passado relatado (PALACIOS, 2014, p. 91). 
A instantaneidade, também chamada por alguns autores (PALACIOS, 2014; MIELNICZUK 2003) de atualização contínua, é uma forte característica do jornalismo digital. Alguns autores como Mielniczuk (2003) associam o nome "jornalismo on-line" exatamente a essa característica de publicação em tempo real, que faz parte do jornalismo na internet (MIELNICZUK, 2003, p. 22). Hoje, quando se quer saber sobre algo ou descobrir se um fato é verdade, a primeira ação é pesquisar na internet. Em seu artigo, Palacios (2003) diz que a atualização contínua na internet “[...] possibilita o acompanhamento contínuo em torno do desenvolvimento dos assuntos jornalísticos de maior interesse." (PALACIOS, 2003, p. 4).

Estar presente em todo lugar, ser onipresente. Essa é a definição simples de ubiquidade. Pavlik (2014) explica que esse conceito associado à mídia significa a possibilidade de acesso de todas as pessoas, em todos os lugares, à rede de comunicação. "Quer dizer que todos podem não apenas acessar notícias e entretenimento, mas participar e fornecer sua própria contribuição com conteúdos para compartilhamento e distribuição global". (PAVLIK, 2014, p. 160). Kerckhove (2009) esclarece que a ubiquidade atua em conjunto com a instantaneidade e que é algo positivo.

\section{Discussão dos dados aplicada ao referencial dos gêneros jornalísticos}

A primeira ação feita durante a análise foi identificar se os conteúdos disponíveis nos sites analisados eram originários de outra mídia ou se eram realmente produzidos para a internet. Acreditava-se que, por haver veículos que eram originários de outras mídias e/ou que faziam parte de um conglomerado, haveria material aproveitado de outros meios. Todavia, os dados coletados mostram que a grande parte dos conteúdos era produzida para a internet. Apenas $1,2 \%$ da amostra não foi produzida especificamente para a Web ou sua origem não era de possível identificação. A análise desta categoria foi feita por meio da identificação da autoria dos textos e do veículo de origem.

Sobre os assuntos abordados nos veículos de comunicação, política $(23,7 \%)$, entretenimento $(12 \%)$ e internacional $(10,7 \%)$ foram os mais tratados. 0 gráfico a seguir mostra quais temas os veículos analisados abordaram ao longo de um mês. 
Gráfico 1 - Temas explorados pelos sites analisados

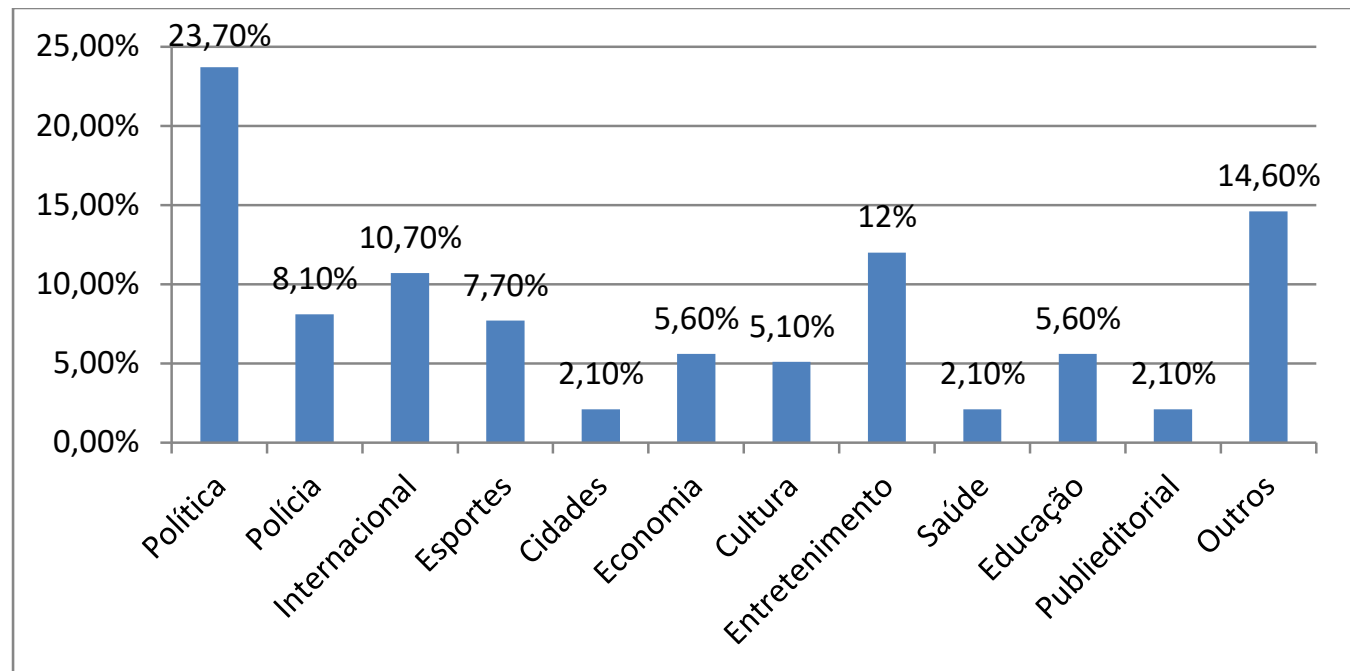

Fonte: Elaborado pela autora.

Nota-se pelo gráfico acima que a categoria outros, proporcionalmente, também teve destaque. Nela, direito (20\%), meio ambiente $(17,6 \%)$ e racismo $(17,6 \%)$ são os temas que mais se destacam. Chamou-nos a atenção a diferença de escolha de tema entre aqueles veículos originários da internet e os originários do impresso, pois enquanto os primeiros são os responsáveis pela maior parte dos conteúdos publicados sobre entretenimento, os segundos foram o que mais publicaram sobre política. Vejamos:

Gráfico 2 - Comparação de temas abordados pelos sites oriundos do impresso e pelos oriundos da internet

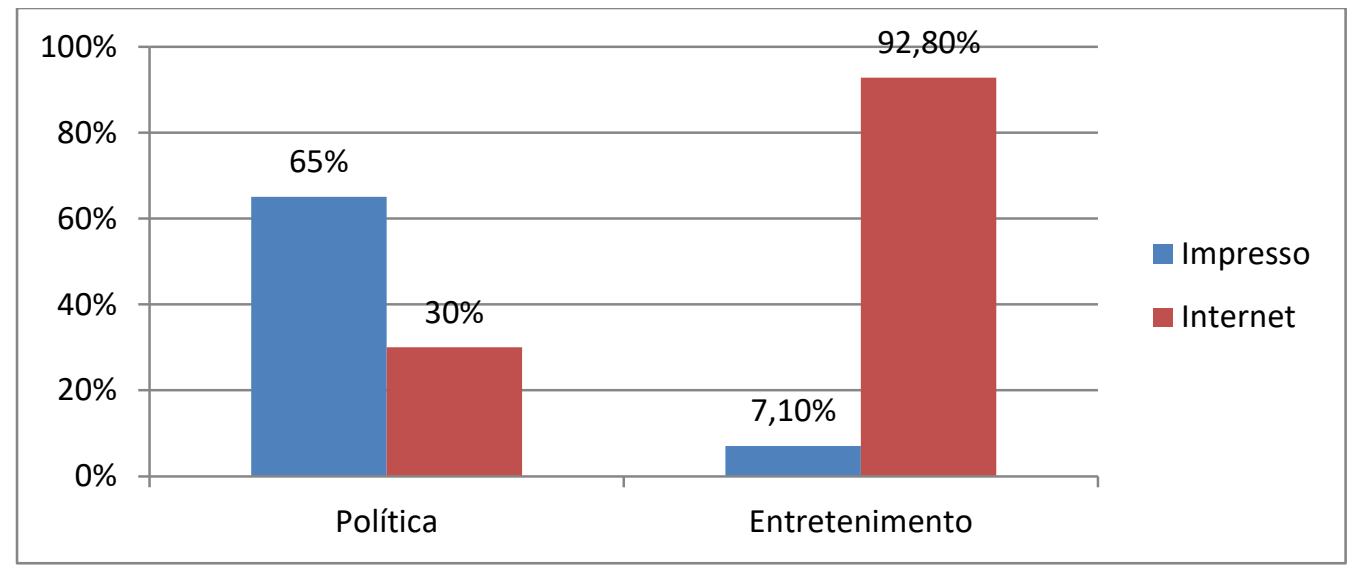

Fonte: Elaborado pela autora.

Pondera-se ainda que, entre os veículos oriundos da internet, o Nexo $(41,1 \%)$ foi o que mais abordou o tema "política". É necessário expor que tais dados condizem com os 
perfis editoriais dos veículos aqui analisados. O Nexo tem em sua essência o fazer jornalístico e a transmissão de informações contextualizadas, enquanto veículos como BuzzFeed e Vice têm maior foco no entretenimento. Sobre a quantidade de entrevistados utilizados, a maior parte dos conteúdos não continha nenhum (32,21\%) ou um (23\%). Além disso, muitos dos textos analisados citavam como fonte outros veículos jornalísticos.

Gráfico 3 - Quantidade de entrevistados presentes nos textos analisados

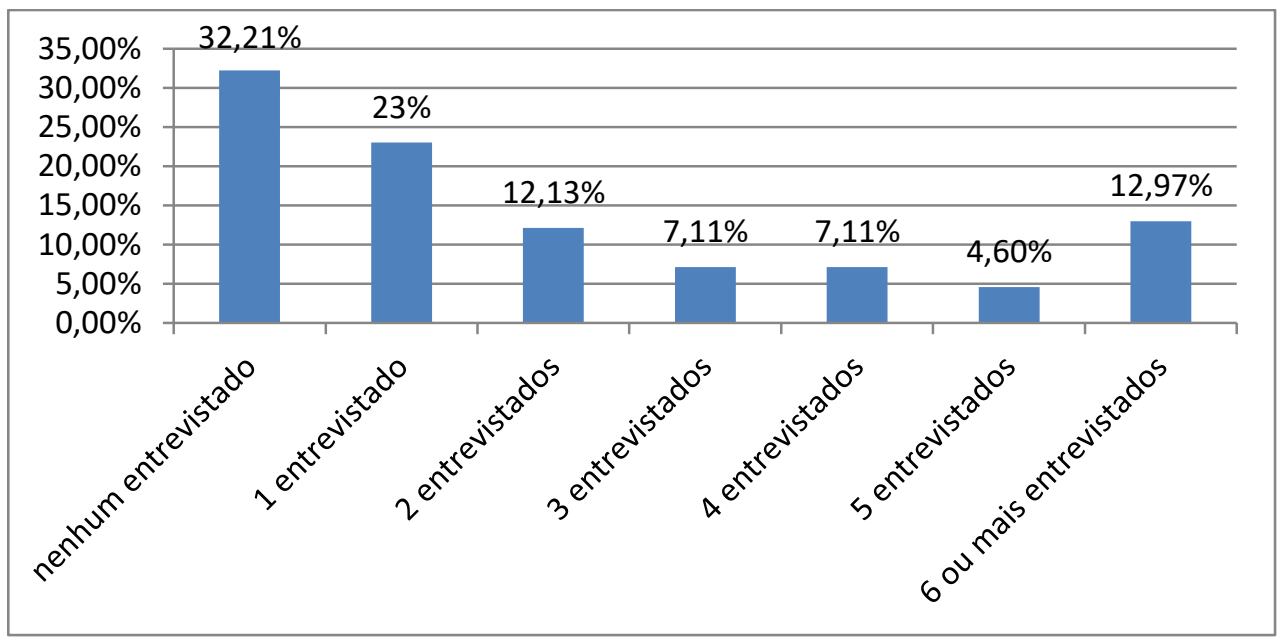

Fonte: Elaborado pela autora.

Sobre os gêneros encontrados nos materiais analisados, há predominância do informativo e do opinativo. Vejamos:

Gráfico 4 - Gêneros jornalísticos presentes nos textos analisados

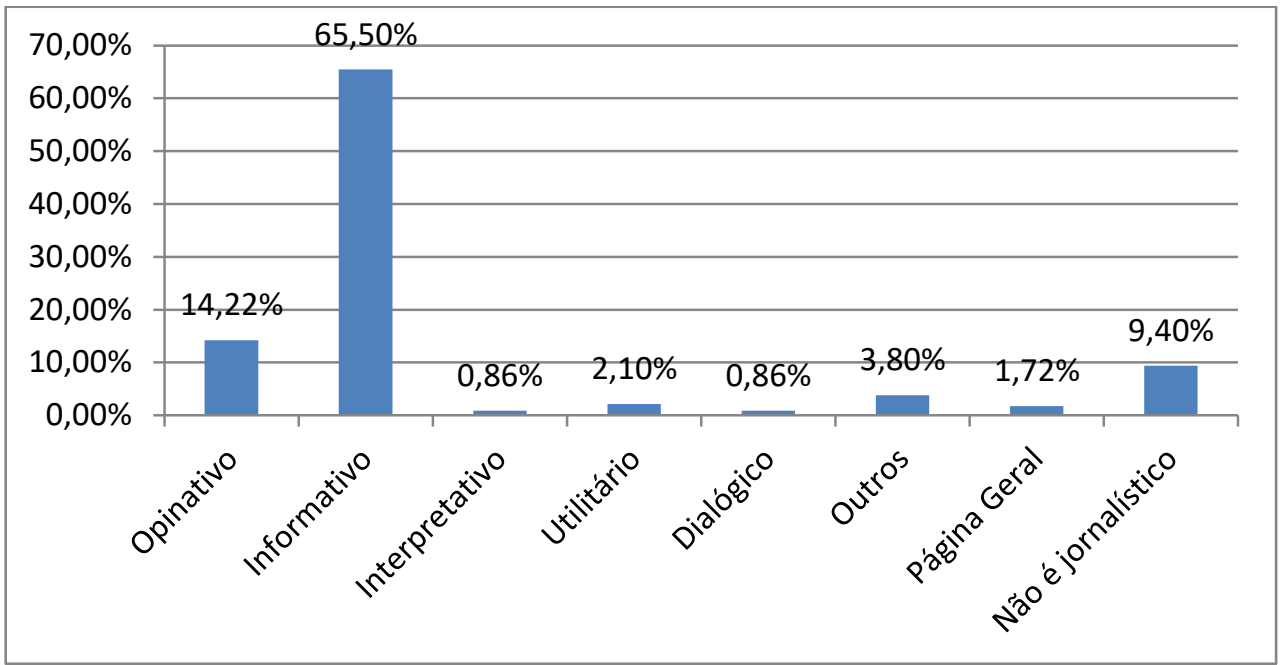

Fonte: Elaborado pela autora. 
Retomamos aqui a explicação de que estamos partindo da classificação de gêneros de Melo e Assis (2010), mas não desconsideramos as outras definições de gêneros existentes, e estas, quando puderem ser aplicadas ao material empírico, serão consideradas, como é o caso do gênero dialógico, presente no gráfico anterior.

Em página geral foram computados os links que não direcionavam para nenhum lugar em específico, e sim para editorias com vários conteúdos. 0 site BuzzFeed foi o que mais teve conteúdos alocados na categoria não é jornalismo, dado que a maioria era composta por testes como 'Faça um brigadeiro e diremos quantos filhos você vai ter'. Já em outros estão aqueles que, a priori, não se encaixam nas classificações existes e, portanto, foram separados para estudos posteriores.

Percebe-se que, no caso dos veículos que surgiram do impresso, o perfil que possuem é levado ao novo meio, a Web, embora com algumas modificações. Assim, estes veículos trabalham predominantemente com assuntos relacionados à política, enquanto os oriundos da internet focam no entretenimento. Entretanto, contraditoriamente, ambos os tipos de veículos utilizam proporcionalmente poucas fontes em suas publicações.

\section{Formatos jornalísticos e suas relações com o webjornalismo}

No item anterior, mostramos os gêneros jornalísticos identificados e agora os relacionaremos com os formatos e as características do webjornalismo. Como visto, o gênero informativo foi o que mais predominou na amostra analisada, fazendo-se presente em $65,5 \%$ dos textos. Sobre os formatos pelos quais se apresentou, a notícia foi o mais utilizado.

Gráfico 5 - Formatos informativos

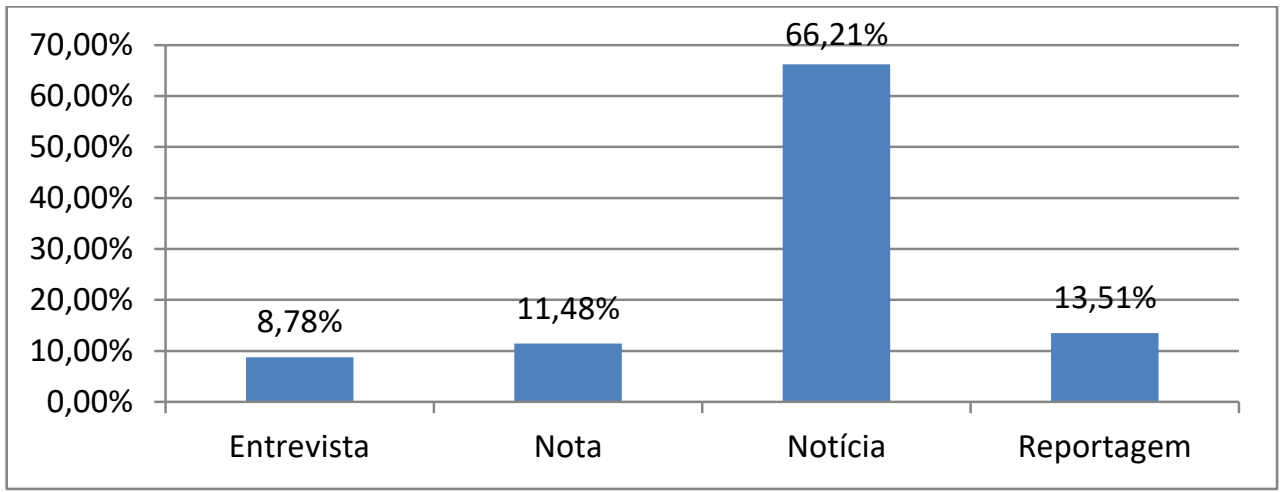

Fonte: Elaborado pela autora. 
Esses formatos jornalísticos informativos, embora tradicionais e existentes em todas as outras mídias, na internet são associados às características específicas, tanto pelas novas formas de apuração quanto de publicação de conteúdos. A notícia Médico de Santa Catarina salva sabiá após massagem cardíaca e vídeo viraliza (GAÚCHAZH, 2017a) só ganhou a mídia após ganhar as redes sociais, ou seja, foi a interatividade que pautou a mídia. Este é um exemplo de atuação do gatewatcher (CANAVILHAS, 2010): quando o público filtra o conteúdo a partir de seus próprios critérios de escolha.

A entrevista 'Eu quero um desfecho justo', diz jovem negro preso no show do Coldplay (VIEIRA, 2017) também foi feita após o caso de racismo ganhar repercussão nas redes sociais. 0 texto segue a estrutura padrão deste formato, ou seja, uma abertura de contextualização do fato seguida por perguntas e respostas, no estilo pingue-pongue. Todavia, foi feita pelo aplicativo WhatsApp, e como imagens há ilustrações. Estas diferenças levam Jorge (2013) a classificar esta estrutura textual de ciberentrevista.

Todavia, seguindo os critérios de classificação estabelecidos como estrutura narrativa, intencionalidade e forma, não identificamos fatos que justificassem uma classificação diferenciada.

Nos 32 textos opinativos encontrados durante o período analisado, o formato com maior predominância foi o artigo de opinião.

Gráfico 6 - Formatos opinativos

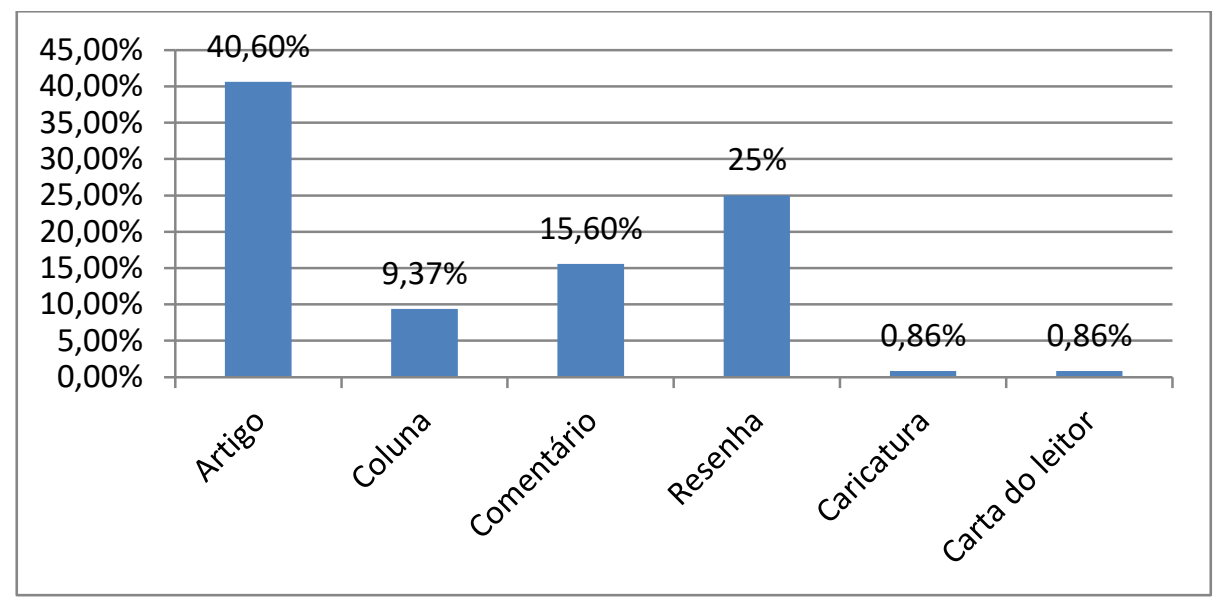

Fonte: Elaborado pela autora.

Tanto os artigos quanto os comentários analisados na amostra seguem estrutura narrativa e estética bem próximas ao do impresso, distinguindo-se em poucos aspectos, 
como o uso de link. Os outros três formatos já apresentaram aspectos que os diferenciaram dos que são encontrados em outros meios de comunicação. A caricatura foi encontrada como um formato complementar a um comentário e a uma notícia; no primeiro caso ambos os formatos estão na esfera opinativa, já o segundo mostra a imbricação entre informação e opinião, o que, para Chaparro (2008), é coerente, pois elas são indissociáveis.

Figura 1 - Notícia com caricatura

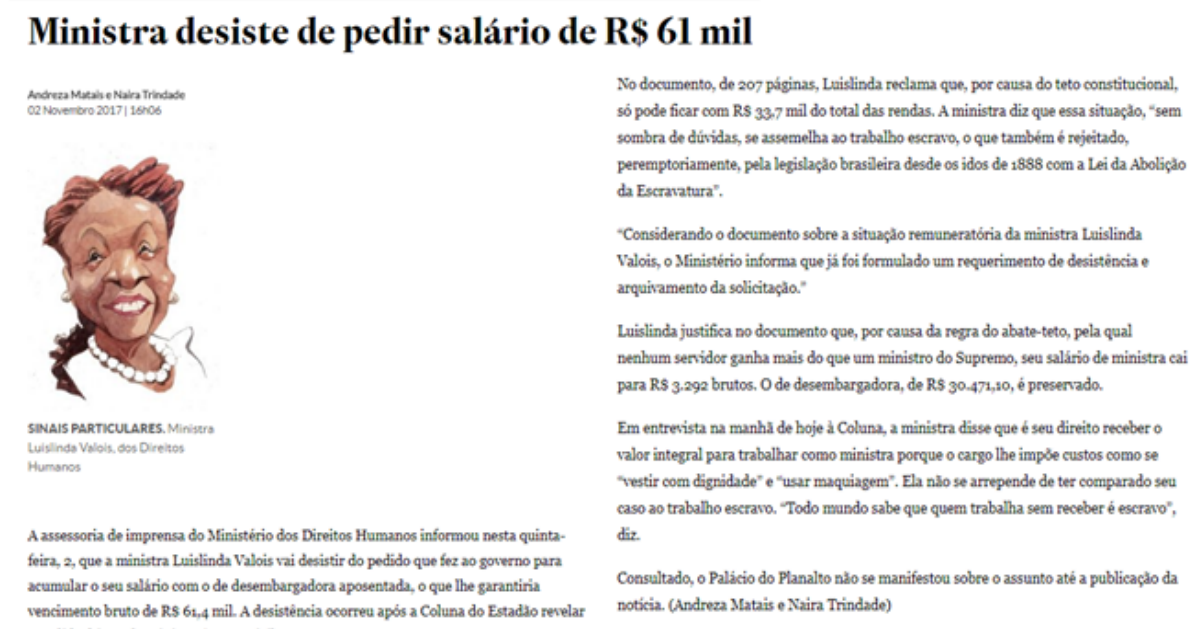

Fonte: Matais e Trindade (2017).

Ressalta-se que o material está publicado no site do Estadão e em uma página chamada de coluna, contudo, neste caso, o material não atende às características de uma coluna, a qual, como mencionado anteriormente, ocupa um espaço fixo e é composta por pequenas notas ácidas e 'furos' de fatos, especialmente da área política e social Nota-se ainda que o texto acima não utiliza nenhuma das características do webjornalismo, não ofertando links, nem formas de interatividade e de personalização, e apresenta recursos limitados de multimidialidade.

A Folha de S.Paulo foi o veículo que mais apresentou o formato coluna: sua estrutura narrativa atende às características que estruturam este formato, é formada por pequenos textos, opinativos, que utilizam recursos linguísticos como a ironia. Contudo, na internet, soma-se a esta estrutura a linguagem hipertextual, que em todos os casos direcionavam o usuário a textos informativos do próprio site relacionados à nota da coluna. Além disso, é acrescentado o uso de slideshow, o qual consideramos um formato técnico (com fotos sequenciadas e legendas que passam conforme a interação do usuário) que pode abrigar 
diversos formatos jornalísticos. Nele pode estar uma dica, uma nota, um roteiro etc. Além disso, ele pode ser utilizado tanto isoladamente, quanto como complementar a outros formatos. Na coluna de Mônica Bergamo, publicada no dia 21 de novembro pela Folha de S.Paulo, há dois slideshows:

Figura 2 - Exemplos de slideshows

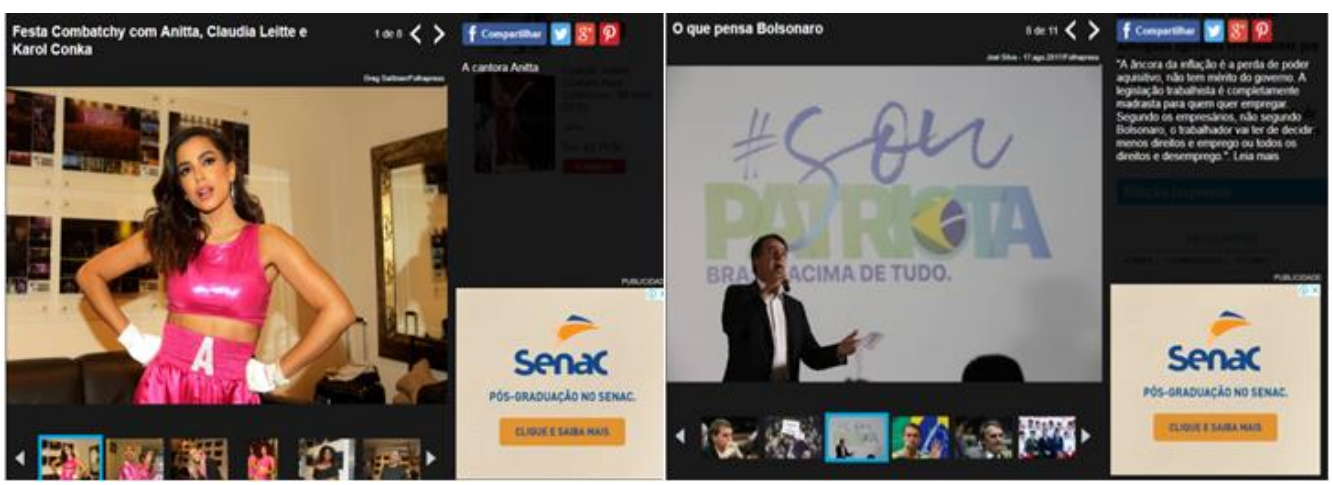

Fonte: Elaborado pela autora.

Na primeira imagem, o slideshow foi utilizado com textos que apenas descrevem as imagens relacionadas, já na segunda foram selecionadas falas públicas do político Jair Bolsonaro, que juntas sistematizam e resumem o seu pensamento (Figura 2). Esses recursos mostram uma maior apropriação da linguagem multimidiática na coluna, mesmo sendo este um formato que tradicionalmente não se associava a estes tipos de recursos. Além disso, ao final do texto ainda há uma dica, a qual, conforme explicado, traz “[...] informações que unem o formato reportagem (relato estendido sobre algum acontecimento) com o formato roteiro (relato resumido sobre as opções de consumo de bens simbólicos." (VAZ, 2010, p. 128-129). Retoma-se que a dica faz parte do gênero utilitário e a coluna do opinativo, o que comprova a coerência com que Bertocchi (2013) afirma que a narrativa na Web é uma estrutura flexível.

Ainda no opinativo foram encontrados os formatos resenha e carta do leitor. 0 último segue o formato tradicional, diferenciando-se apenas por ter links que direcionam o usuário ao texto relacionado ao comentário do leitor. Já as resenhas que fazem parte da amostra se configuraram de distintas formas, todas fazendo análises de um produto cultural, mas apresentando-os de diferentes maneiras.

Por exemplo, enquanto Vem aí: REMAKE traz informações sobre a nova série, de forma simples, em menos de cinco parágrafos e sem recursos 
multimidiáticos, o texto A intrigante história real por trás de 'Alias Grace', série baseada no livro de Margaret Atwood trabalha de maneira oposta. Em uma extensa resenha, com mais de 40 parágrafos, a narrativa contém trailer da série, fotografias e imagens de documentos, explorando a linguagem multimidiática, além de trechos de entrevistas e da minissérie. Ademais, há dados do enredo e do reconhecimento dele por meio de indicação a prêmios. A crítica trabalhada com mais profundidade foi bem apreciada pelos usuários. (PEREIRA, 2018, p.150).

Figura 3 - Comentários sobre a resenha

\section{A intrigante história real por trás de 'Alias Grace', série baseada no livro de Margaret Atwood}

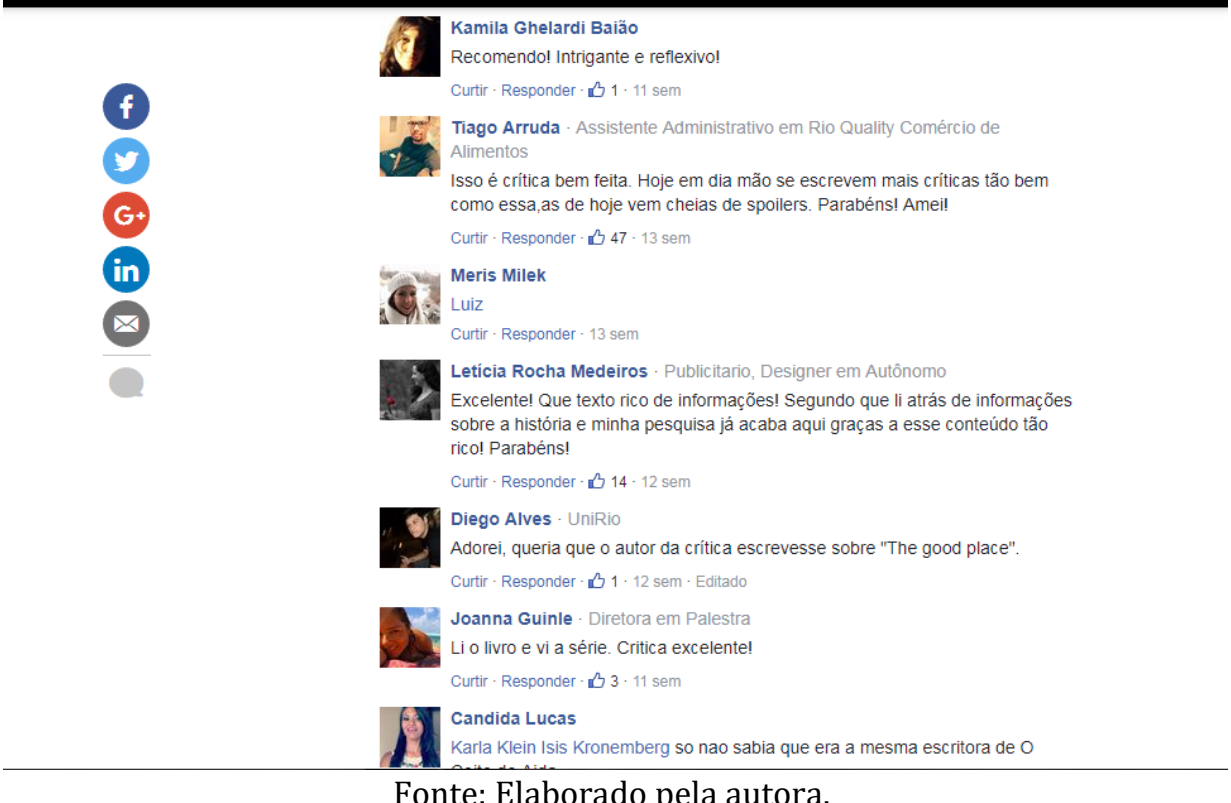

Fonte: Elaborado pela autora.

Pertencentes ao gênero utilitário foram encontrados dois formatos: o roteiro $(1,29 \%)$ e o serviço $(0,86 \%)$. 0 serviço foi encontrado tanto em complemento às notícias, quanto de forma autônoma, como é o caso do texto Atrações, preços e telão: saiba como será a fan fest na Arena para Lanús x Grêmio (GAÚCHAZH, 2017b), que traz informações sobre o evento e valores de ingressos por setor, entre outras informações. Já o roteiro, como De 1900 a 2000, veja lugares para viajar no tempo em São Paulo (RIBEIRO; SANCHEZ, 2017), publicado pela Folha de São Paulo, se diferencia por possibilitar que o usuário, após obter informações sobre os bens simbólicos, acesse-os diretamente e encontre mais informações por meio de seus sites ou redes sociais, podendo, por exemplo, realizar reservas de mesas em restaurante. Além disso, este texto em específico trouxe como diferencial uma playlist, recurso sonoro pouco usado no jornalismo, que, no caso exemplificado, traz o contexto de uma época histórica. 
Ainda sobre os formatos tradicionais que já haviam sido anteriormente classificados, foi encontrado um perfil pertencente ao gênero interpretativo e, pertencentes ao gênero diversional, uma história de interesse humano e uma colorida. 0 perfil foi publicado pela Zero Hora e é sobre um jogador de futebol aposentado que virou empresário do ramo da reciclagem. 0 texto traz apenas a foto como recurso multimidiático, não trabalha com links nem formas de personalização, e a estrutura narrativa é claramente pertence ao formato perfil, pois aborda um único personagem, relatando feitos da vida dele e trazendo suas características particulares. A frase Beto dispensa os filtros ao falar da vida boêmia dos tempos de jogador exemplifica.

Destaca-se ainda que a Folha de São Paulo publicou, de modo complementar a uma notícia, uma cronologia, não sendo utilizada como um formato autônomo, e sim como complementar. A cronologia é considerada por Melo e Assis (2010) um formato pertencente ao gênero interpretativo. No caso citado, ela estava como complemento a uma notícia, pertencente ao gênero informativo, o que mostra, conforme Bertocchi (2013), que, na rede, a narrativa jornalística é um processo dinâmico.

Como história de interesse humano, classificamos o texto $A$ construção de um assassino em série nos anos 20 (DECLERCQ, 2017) publicado pela Vice no dia 26 de novembro de 2017. O texto conta a história de um negro preso por supostamente ter cometido vários assassinatos, mas sem ter ido a julgamento. 0 texto foca a relação do personagem com a acusação, mas a partir desse fato traz dados sobre o personagem, contextualizando sua história de vida por meio de uma linguagem que utiliza recursos literários.

Já o texto $O$ debate público convocado pelo MBL via WhatsApp foi um triste simulacro de democracia, publicado em 17 de novembro de 2017, também pela Vice, foi enquadrado como história colorida. 0 texto conta o fato a partir do cenário em que ele está inserido, fazendo uso de uma linguagem literária, o que pode ser visualizado em trechos como: "O vão livre da Câmara, um espaço ao ar livre e coberto, um tanto pomposo, era dividido em duas alas" (VICE, 2017) e "As nuvens dos verões apocalípticos paulistanos pesavam pretas no céu, mas as condições climáticas não se alteraram até o fim de mais uma audiência pública do projeto Escola Sem Partido" (VICE, 2017). 


\section{Considerações Finais}

A macroanálise permitiu a constatação de que no webjornalismo ainda há a predominância dos gêneros hegemônicos (informativo e opinativo) e dos formatos tradicionais (nota, notícia, artigo e crônica). Por outro lado, esta fase de análise também nos mostrou que, mesmo que em menor porcentagem, a web abriga formatos inicialmente não muito associados a ela, como, por exemplo, a história colorida e a de interesse humano. Entretanto, acreditamos que, até o momento, os dados mais ricos que obtivemos da coleta foram: (1) a identificação de formatos geralmente trabalhados de modo autônomo e que estavam complementares a outros; (2) o uso conjunto de diferentes formatos que pertenciam a esferas comunicativas distintas e que ao serem associados não se descaracterizaram nem colocaram em questão a qual gênero pertenciam, como é o caso da notícia com a cronologia e da coluna com a dica.

Prova disso é que os gêneros hegemônicos em seus formatos tradicionais continuam predominando nos conteúdos dos webjornais. Em contrapartida, encontramos diversos exemplos que nos possibilitaram pensar e refletir a prática jornalística e suas tendências, a partir de recursos tecnológicos como o slideshow, que podem abrigar diversos formatos.

Ficou nítido durante o estudo que a reconhecida classificação de Melo e Assis (2010) contribui para pesquisas empíricas, servindo de norte para o desenvolvimento de análises e, principalmente, abrindo brechas para que se pense os gêneros e formatos na atualidade.

Nessa perspectiva, contribui pensar na existência ou inexistência do gênero dialógico. A partir dos dados da macroanálise, identificamos que ele pode existir, embora precise ser mais bem avaliado e ter suas características e princípios delineados com mais clareza.

\section{Referências}

BELTRÃO, Luiz. Iniciação à filosofia do jornalismo. Rio de Janeiro: Agir, 1960

BELTRÃO, Luiz. Jornalismo interpretativo. Porto Alegre: Sulina, 1976.

BELTRÃO, Luiz. Jornalismo interpretativo: filosofia e técnica. 2. ed. Porto Alegre: Sulina, 1980.

BERGAMO, Mônica. Bolsonaro viajará a Hong Kong, Japão e Coreia do Sul em 2018. Folha de São Paulo, São Paulo, 21 nov. 2017. 
BERTOCCHI, Daniela. Gêneros jornalísticos em espaços digitais. In: ACTAS DA SOPCOM, 4. 2005, Porto. Livro de Atas de Conferência Nacional. Associação Portuguesa de Ciências da Comunicação - SOPCOM, 2005, p. 1287-1299

BERTOCCHI, Daniela. Dos dados aos formatos: um modelo teórico para o desenho do sistema narrativo no jornalismo digital. 2013. Tese (Doutorado em Ciências da Comunicação) - Escola de Comunicações e Artes, Universidade de São Paulo, São Paulo, 2013.

BERTOCCHI, Daniela. A narrativa jornalística no ciberespaço: transformações, conceitos e questões. 2006. Dissertação (Mestrado em Ciências da Comunicação) -Universidade do Minho, Braga, 2006.

CANAVILHAS, João. Do jornalismo on-line ao webjornalismo: formação para a mudança. Lisboa: BOCC, 2010.

CANAVILHAS, João (org.). Webjornalismo: 7 características que marcam a diferença. Covilhã: Labcom, 2014.

CHAPARRO, Manuel Carlos. Sotaques d'aquém e d'além mar: percursos e gêneros do jornalismo português e brasileiro. Santarém: Jortejo, 2000.

CHAPARRO, Manuel Carlos. Sotaques d'aquém e d'além mar: percursos e gêneros jornalísticos do jornalismo português. São Paulo: Summus, 2008.

COSTA, Lailton Alves. Gêneros jornalísticos. In: MELO, José Marques de; ASSIS, Francisco de (org.). Gêneros jornalísticos no Brasil. São Bernardo do Campo: Universidade Metodista de São Paulo, 2010.

DELCOLLI, Caio. A intrigante história real por trás de 'Alias Grace', série baseada no livro de Margaret Atwood. [S. l.]: HuffPost Brasil, 4 nov. 2017.

DECLERCQ, Marie. A construção de um assassino em série nos anos 20. [S. l.]: Vice Brasil, 26 nov. 2017.

GAÚCHAZH. Médico de Santa Catarina salva sabiá após massagem cardíaca e vídeo viraliza. Porto Alegre: Grupo RBS, 10 nov. 2017a.

GAÚCHAZH. Atrações, preços e telão: saiba como será a fan fest na Arena para Lanús x Grêmio. Porto Alegre: Grupo RBS, 24 nov. 2017b.

HERRERA, Inma Martin. Ciberredación periodística: nuevo lenguaje para un nuevo medio. Revista Latinoamericana de Comunicación CHASQUI, Quito, n. 92, p. 24-29, 2005.

JORGE, Thaís Mendonça. Mutação no jornalismo: como a notícia chega à internet. Brasília: UnB, 2013. 
KERCKHOVE, Derrick de. A pele da cultura: investigando a nova realidade eletrônica. São Paulo: Anablume, 2009.

LONGHI, Raquel Ritter. Slideshow como formato jornalístico no webjornalismo. Famecos, Porto Alegre, v. 18, n. 3, p. 782-800, 2011.

LONGHI, Raquel Ritter. Os nomes das coisas: em busca do especial multimídia. Estudos em Comunicação, Paraná, v. 2, n. 7, p. 149-161, 2010a.

LONGHI, Raquel Ritter. Bearing witness, jornalismo em flash e formatos da linguagem jornalística digital. Contracampo, Niterói, n. 21, p. 191-204, 2010 b.

LONGHI, Raquel Ritter. A convergência de linguagens nos especiais do Clarín.com. Revista de Estudos da Comunicação, Curitiba, v. 11, n. 25, p. 157-166, 2012.

LORENZ, Mirko. Personalização: análise aos 6 graus. In: CANAVILHAS, João (org.). Webjornalismo: 7 características que marcam a diferença. Covilhã: Labcom, 2014.

MATAIS, Andreza; TRINDADE, Naira. Ministra desiste de pedir salário de 61 mil. 0 Estado de São Paulo, São Paulo, 2 nov. 2017.

MELO, José Marques de. Jornalismo opinativo: gêneros opinativos no jornalismo brasileiro. 3. ed. Campos do Jordão: Mantiqueira, 2003.

MELO, José Marques de; ASSIS, Francisco de. Gêneros jornalísticos no Brasil. São Paulo: Universidade Metodista, 2010.

MIELNICZUK, Luciana. Jornalismo na web: uma contribuição para o estudo do formato da notícia na escrita hipertextual. 2003. Tese (Doutorado em Comunicação e Culturas Contemporâneas) - Faculdade de Comunicação, Universidade Federal da Bahia, Salvador, 2003.

NOCI, Javier Diaz. Los géneros ciberperiodísticos: una aproximación teórica a los cibertextos, sus elementos y su tipología. In: CONGRESO IBEROAMERICANO DE PERIODISMO DIGITAL, 2., 2004, Santiago de Compostela. Anais [...]. Santiago de Compostela: [s.n], 2004. p. 47-69.

PALACIOS, Marcos. Ruptura, continuidade e potencialização no jornalismo on-line: o lugar da memória. In: MACHADO, Elias; PALACIOS, Marcos (org.). Modelos do jornalismo digital. Salvador: Calandra, 2003, p. 1-17.

PALACIOS, Marcos. Jornalismo, memória e história na era digital. In: CANAVILHAS, João (org.). Webjornalismo: 7 características que marcam a diferença. Covilhã: Labcom, 2014. cap. 4, p. 89-110.

PAVLIK, John. Ubiquidade: o 7ํㅡ princípio do jornalismo na era digital. In: CANAVILHAS, João cap. 7, p. 159-184. (org.). Webjornalismo: 7 características que marcam a diferença. Covilhã: Labcom, 2014. 
PEREIRA, Clarissa Josgrilberg. Entre limites e possibilidades: o estudo dos gêneros jornalísticos nas fronteiras de Mato Grosso do Sul. 2013. Dissertação (Mestrado em Comunicação Social) - Programa de Pós-Graduação em Comunicação Social, Universidade Metodista de São Bernardo do Campo, São Bernardo do Campo, 2013.

PEREIRA, Clarissa Josgrilberg. Jornalismo Digital e novas tecnologias: estudo de gêneros e formatos nos principais sites jornalísticos brasileiros. 2018. Tese (Doutorado em Comunicação Social) - Programa de Pós-Graduação em Comunicação Social, Universidade Metodista de São Bernardo do Campo, São Bernardo do Campo, 2018.

RIBEIRO, Amanda; SANCHEZ, Leonardo. De 1900 a 2000, veja lugares para viajar no tempo em São Paulo. Folha de São Paulo, São Paulo, 10 nov. 2017.

ROST, Alejandro. Interatividade: definições, estudos e tendências. In: CANAVILHAS, João (org.). Webjornalismo: 7 características que marcam a diferença. Covilhã: Labcom, 2014. cap. 3, p. 53-88.

SALAVERRÍA, Ramón. Redacción periodística en internet. Pamplona: Ediciones Universidad de Navarra, 2005.

SALAVERRÍA, Ramón. Multimedialidade: informar para cinco sentidos. In: CANAVILHAS, João (org.). Webjornalismo: 7 características que marcam a diferença. Covilhã: Labcom, 2014. cap. 2, p. 25-52.

SEIXAS, Lia. Redefinindo os gêneros jornalísticos: proposta de novos critérios de classificação. Salvador: Labcom, 2009a.

SEIXAS, Lia. Por uma outra classificação: gêneros discursivos jornalísticos e gêneros discursivos jornálicos. Galáxia, São Paulo, n. 18, p. 70-84, 2009 b.

SEIXAS, Lia. Para compreender gêneros jornalísticos: teorias do jornalismo e midiologia. In: SEIXAS, Lia; PINHEIRO, Najara Ferrari (org.). Gêneros: um diálogo entre comunicação e linguística. Florianópolis: Insular, 2013.

URETA, Ainara Larrondo. Los géneros en la redacción ciberperiodística: contexto, teoría y práctica actual. Espanha: Universidad del País Vasco, 2010.

\section{VICE. 0 debate público convocado pelo MBL via Whatsapp foi um triste simulacro de democracia. [S.L]. 17 nov. 2017.}

VAZ, Tyciane Cronemberger Viana. Jornalismo utilitário - teoria e prática: fundamentos, história e modalidades de serviço na imprensa brasileira. 2013. Tese (Doutorado em Comunicação Social) - Programa de Pós-Graduação em Comunicação Social, Universidade Metodista de São Paulo, São Bernardo do Campo, 2013.

VAZ, Tyciane Cronemberger Viana. Gênero utilitário. In: MELO, José Marques de; ASSIS, Francisco de. Gêneros jornalísticos no Brasil. São Bernardo do Campo: Universidade Metodista de São Paulo, 2010, 125-140. 
VIEIRA, Gabriel dos Santos. 'Eu quero um desfecho justo', diz jovem negro preso no show do Coldplay. [Entrevista cedida a] Taís Seibt. [S. l.]: Agência Pública, 17 nov. 2017.

WERNECK, Humberto. A arte de sujar os sapatos. In: TALESE, Gay. Fama e anonimato. 2. ed. São Paulo: Companhia das Letras, 2004.

\title{
Cyberergenders in Brazilian Web \\ Newspapers: a study of the top ten media
}

\begin{abstract}
The making of journalism is constantly changing and its transformations are optimized by the technologies of information and communication. In this way, the current network society that experiences a convergence of culture modifies its habits of consumption and production of content. This scenario was the starting point to this research, generating the will to comprehend the relationships between webjournalistic products and the current classifications of genres and formats. For this purpose, an analysis sheet was created based on Palacios and Canavilhas, and on the classifications of journalistic genres, which allowed the freedom and direction for understanding the journalistic practices used by the ten main online newspapers in Brazil: Folha de S. Paulo, Estadão, Gazeta, Zero Hora, O Globo, BuzzFeed, Vice, HuffPost Brasil, Nexo and Agência Pública. This research analysed 232 units, which generated a data bank with more than 8,000 units of information. This process is a macroanalysis. From the proceedings presented above, we identified, in the production of hard news in Brazilian web journalism, the predominance of hegemonic formats and genres. However, we also identify that the formats in the web journalism act with fluidity between the genres of the newspaper, sometimes serving as a complement, sometimes being the absolute conductors of the genres.
\end{abstract}

\section{Keywords}

Web journalism. Journalistic genres. Journalistic formats.

\section{Autoria para correspondência}

Clarissa Josgrilberg Pereira

clarissa_jpereira@hotmail.com 


\section{Como citar}

PEREIRA, Clarissa Josgrilberg. Cibergêneros nos webjornais brasileiros: um estudo dos dez primeiros veículos. Intexto, Porto Alegre, n. 52, e-90530, jan./dez. 2021. DOI: http://dx.doi.org/10.19132/18078583202152.90530

Recebido em 24/02/2019

Aceito em 06/12/2019

(c) $(1) \Theta$ 